\title{
Comparative analysis of transcriptional profiles of Schistosoma japonicum adult worms derived from primary-infected and re-infected water buffaloes
}

Yudan Mao, Chuanchuan He, Hao Li, Ke Lu, Zhiqiang Fu, Yang Hong, Yamei Jin, Jiaojiao Lin, Xin Zhang and Jinming Liu*

\begin{abstract}
Background: Schistosoma japonicum (S. japonicum) is an important zoonotic parasite that is prevalent in China and parts of Southeast Asia. Water buffaloes are an important reservoir and the main transmission sources of S. japonicum. However, self-curing and resistance to re-infection have been observed in water buffaloes.

Results: In this study, we compared the morphometry and differences in transcriptional expression of adult S. japonicum worms recovered from primary-infected and re-infected water buffaloes using Illumina RNA-sequencing (RNASeq) technology. Results of morphometry analysis revealed that adult S. japonicum worms recovered from re-infected water buffaloes were runtish with smaller organs. The ventral length of male worms was shorter in re-infected buffaloes ( $328 \pm 13$ vs $273 \pm 8 \mu \mathrm{m}, P<0.05)$, and in female worms the oral sucker length ( $44 \pm 3$ vs $33 \pm 5 \mu \mathrm{m}, P<0.05$ ), ovary length (578 \pm 23 vs $297 \pm 27 \mu \mathrm{m}, P<0.05)$ and width $(150 \pm 8$ vs $104 \pm 9 \mu \mathrm{m}, P<0.05)$ were shorter, with fewer eggs in the uteri ( $41 \pm 2$ vs $12 \pm 1, P<0.05$ ). Of 13,605 identified genes, 112 were differentially expressed, including 51 upregulated and 61 downregulated genes, in worms from re-infected compared with primary-infected water buffaloes. Gene ontology (GO) enrichment analysis revealed that GO terms such as "oxidation-reduction process", "calciumdependent phospholipid binding", "lipid binding" and "calcium ion binding" were significantly enriched in downregulated genes, whereas GO terms related to metabolism and biosynthesis were significantly enriched in upregulated genes. The results revealed that the downregulation of some important genes might contribute to a reduction in worm numbers and maldevelopment of surviving worms in re-infected water buffaloes. Furthermore, upregulation of genes related to metabolic processes and biosynthesis might be a compensatory mechanism of worms in disadvantageous environments.
\end{abstract}

Conclusions: To our knowledge, our results present the first large-scale transcriptional expression study identifying the differences between adult S. japonicum worms from primary-infected and re-infected water buffaloes, and particularly emphasize differential expression that may affect the survival and growth of worms in re-infected water buffalo. This will provide new insight into screening for anti-schistosome targets and vaccine candidates.

Keywords: Comparative analysis, Primary-infected, Re-infected, RNA-Seq, Schistosoma japonicum, Water buffalo

\footnotetext{
*Correspondence: jimyliu@shvri.ac.cn
}

Shanghai Veterinary Research Institute, Chinese Academy of Agricultural

Sciences, Key Laboratory of Animal Parasitology, Ministry of Agriculture,

Shanghai 200241, People's Republic of China 


\section{Background}

Schistosomiasis, caused by infections with Schistosoma species, is endemic in over 70 countries and territories located in tropical and subtropical regions and remains a major public health problem worldwide [1]. Schistosoma japonicum is a zoonotic parasite that is prevalent in China and parts of Southeast Asia [2]. It has been reported that over 40 species of wild and domestic animals can become infected with S. japonicum [3, 4]. Generally, praziquantel (PZQ) is the only effective chemotherapeutic drug against schistosomiasis. However, its utility is limited in areas with high re-infection and resistance rates. Additionally, low susceptibility of Schistosoma mansoni and S. japonicum to PZQ has been induced after mass drug administration programmes $[5,6]$. Therefore, novel targets for drugs and vaccines to treat and eradicate schistosomiasis are urgently required.

Infection with S. japonicum causes serious economic losses to livestock farms. Many investigations have revealed that domestic animals, bovines in particular, are the major infectious source and play the most important role in the transmission of schistosomiasis in China $[7,8]$. Thus, water buffaloes have been considered a target animal for schistosomiasis control in China for several decades [9]. A veterinary vaccine for domesticated bovines that blocks transmission would provide an effective approach to schistosomiasis control. Several research groups have focused on the development of efficient vaccines for buffaloes $[10,11]$. However, the level of protection of these vaccines needs further improvement. Lack of knowledge about schistosome biology and host-parasite relationships in bovines remains an obstacle for vaccine development.

Recently, many public databases on the genomes, transcriptomes and proteomes of Schistosoma species, in particular S. mansoni and S. japonicum [12, 13], have been released, which has proved pivotal for the understanding of schistosome biology. In the past decade, a number of studies on gene expression and proteomic profiling of Schistosoma species have been performed using various analytical approaches. These studies mainly focus on expression patterns and features of sex-dependent, tissue-specific, host-associated and strain-specific genes [12, 14-16]. The findings have facilitated improved understanding of the molecular basis of schistosome developmental biology, host-parasite interactions and schistosomiasis pathogenesis. For example, studies from our research group have identified numerous differentially expressed genes (DEGs) that may influence parasite survival and development of schistosomula from susceptible BALB/c mice, less susceptible Wistar rats and resistant reed voles using comparative proteomic [17] and microarray analyses [18]. We have also examined gene expression profiles of S. japonicum worms derived from the natural hosts yellow cattle and water buffalo using comparative analysis of microarrays [19].

Water buffaloes are numerous and widely distributed in schistosomiasis-endemic regions and are a major reservoir for Schistosoma species in China [8]. Compared with other natural hosts, such as yellow cattle, goats and rabbits, water buffaloes are less susceptible to infection [20]. In addition, previous researchers reported self-curing in water buffaloes, as they observed decreases in infection rates with age [21] and age-related resistance to re-infection after PZQ treatment [22]. Recently, we observed a reduction of over $97 \%$ in the S. japonicum worm burden, shorter female worms, and a reduction of over $87.7 \%$ in egg counts in re-infected buffaloes [23]. Strong type-2 immune responses at the site of cercarial penetration have also been reported in challenged water buffaloes [24], which is significantly different from observations in other animal models such as mice. We also found that reinfected water buffaloes had significantly higher levels of interleukin (IL)-4, IL-10, interferon (IFN)- $\gamma$ and specific immunoglobulin G (IgG) antibodies before challenge infection [23]. Here, we performed comparative analyses of gene expression profiles of $S$. japonicum adult worms from primary-infected and re-infected water buffaloes using deep RNA-transcriptome sequencing (RNA-Seq) technology. Our results will be of significance for understanding the mechanism of resistance and host-parasite relationships in re-infected water buffaloes and could provide a valuable resource for the identification of genes functionally related to parasite development in water buffaloes as well as the screening of anti-schistosome drug targets and vaccine candidates.

\section{Methods}

\section{Infection protocol and parasite collection}

The parasites used in this study were collected from animals in the primary infection group (referred to in the previous study as the control group) and the re-infection group in the second trial of a study performed in 2017 to observe the degree of resistance of water buffaloes to re-infection with $S$. japonicum, as reported in our previous publication [23]. The infection protocol is summarized in Fig. 1 and briefly described as follows: six 15- to 18-month-old male water buffaloes (Bubalus bubalis) were purchased from non-schistosome-endemic areas in Nantong, Jiangsu Province, China and randomly divided into either the primary infection group or the re-infection group. Schistosoma japonicum cercariae used in all infections were shed from infected Oncomelania hupensis snails purchased from the Hunan Institute of Parasitic Diseases (Yueyang, China). Animals in the re-infection group were infected with $3000 \mathrm{~S}$. japonicum cercariae on 


Pe-
infection
infection
Fig. $\mathbf{1}$ Schedule of animal infection, treatment and sacrifice. The
primary infection and re-infection strategies for different groups
were as shown. Briefly, re-infection group were infected with 3000
S.japonicum cercariae on day 0 and on day 95 and treated with PZQ
on day 54 and day 152; primary infection group were not infected
initially but were treated with PZQ at the same time points (on day 54
and day 152 ). On day 185, all animals were infected percutaneously
with 3000 100 cercariae. Animals were euthanized on day 255
(n=3)

day 0 and on day 95 and treated with PZQ on day 54 and day 152. Water buffaloes in the primary infection group were not infected initially but were treated with PZQ at the same time points. In order to remove all S. japonicum worms in infected water buffaloes, PZQ was orally administered twice at $24 \mathrm{~h}$ intervals in each treatment at a dose of $25 \mathrm{mg} / \mathrm{kg}$ body weight up to a maximum of 10 g. On day 185, all animals were infected percutaneously with $3000 \pm 100$ cercariae. Animals were euthanized on day 255. Worms were obtained from three animals in the primary infection group and three animals in the reinfection group and designated $\mathrm{C} 1, \mathrm{C} 2, \mathrm{C} 3, \mathrm{~T} 1, \mathrm{~T} 2$ and T3, respectively. All parasites were manually washed twice with phosphate-buffered saline to remove residual host debris. Some worms were immediately preserved in RNAlater $^{\circledR}$ (Invitrogen, Carlsbad, CA, USA) and stored in liquid nitrogen for subsequent RNA extraction. Five pairs of worms (five males and five females) from each animal were fixed with $10 \%$ neutral buffered formalin for morphological analysis.

\section{Morphological comparisons of worms collected from primary-infected and re-infected water buffaloes}

A total of 30 pairs of worms, including 30 males and 30 females, were used for morphological comparisons. The paired worms were placed in ice water to separate the males and females. Slide specimens were prepared using the conventional method $[25,26]$ and observed under a microscope equipped with an automatic ACT-2U camera (Nikon, Tokyo, Japan). The total worm length, along with the dimensions of the oral sucker, ventral sucker and ovary were measured using NIS-Elements, a Nikon image analysis software. The number of eggs in the uterus of each female was counted. Data are expressed as the mean \pm standard deviation. The results for each group were compared using Student's t-tests in Excel
2013 (Microsoft Inc., Redmond, WA, USA) to examine intergroup differences. $P$-values $<0.05$ were considered statistically significant.

Total RNA isolation, qualification and transcriptomic library construction

Total RNA was extracted from individual worms collected from each water buffalo using TRIzol Reagent (Invitrogen), and contaminating genomic DNA was removed from RNA samples by treatment with RNasefree DNase I (New England Biolabs, Ipswich, MA, USA). RNA degradation and contamination were monitored on $1 \%$ agarose gels, a NanoPhotometer ${ }^{\circledR}$ spectrophotometer (IMPLEN, Westlake Village, CA, USA) and a Qubit $^{\circledR}$ RNA Assay Kit with a Qubit ${ }^{\circledR} 2.0$ Fluorometer (Life Technologies, Carlsbad, CA, USA). Before RNA library construction, RNA integrity was assessed using an RNA Nano 6000 Assay Kit and Bioanalyzer 2100 system (Agilent Technologies, Santa Clara, CA, USA). RNA with an RNA integrity number $(\mathrm{RIN})>7.0$ were considered of high enough quality for transcriptomic library construction and RNA sequencing according to the manufacturer's instructions.

\section{Transcriptomic library preparation}

For library construction, mRNA was purified from $3 \mu \mathrm{g}$ of total RNA of each sample using poly-T oligo-attached magnetic beads (New England Biolabs) [27]. Transcriptome sequencing libraries were generated using an Illumina NEBNext ${ }^{\circledR}$ UltraTM RNA Library Prep Kit (New England Biolabs) according to the manufacturer's instructions and index codes were added to attribute the sequences to the corresponding sample. Briefly, purified mRNA was cut into fragments and the cleaved mRNA fragments were reverse-transcribed into first-strand cDNA using random hexamers, followed by synthesis of double-strand cDNA. After blunting ends, the 250 to 300 bp fragments were purified using the AMPure XP system (Beckman Coulter, Brea, CA, USA). The purified cDNA fragments were then linked using an NEBNext Adaptor (New England Biolabs) with a hairpin loop structure and amplified by PCR. The AMPure XP system (Beckman Coulter) was used to purify the PCR products and the sample library quality was assessed using an Agilent Bioanalyzer 2100 system.

\section{Transcriptome sequencing and data analysis}

Equal amounts of the 12 transcriptomic libraries were pooled and sequenced using an Illumina $\mathrm{HiSeq}^{\mathrm{TM}} 2000$ (Illumina, San Diego, CA, USA) sequencing platform [28]. Raw reads in fastq format were processed using in-house perl scripts. These sequencing data are available at the NCBI Sequence Read Archive (SRA) database 
(www.ncbi.nlm.nih.gov/sra) under the accession number SRP168979. After calculating the Qpred $\leq 20$ (Q20), Qpred $\leq 30(\mathrm{Q} 30)$ and GC content of each sequence, clean data were obtained by removing the adapter from each sequence as well as any reads containing poly- $\mathrm{N}$. Low quality reads were removed and the high quality clean reads were independently mapped twice to the genomic data (WormBase ParaSite, http://parasite. wormbase.org/Schistosoma_japonicum_prjea34885/ Info/Index/) using Hisat2 v.2.0.5 [29]. Mapped reads for each sample were assembled using StringTie v.1.3.3b with a reference-based approach [30]. The expression level of each gene was estimated using the fragments per kilobase of transcript sequence per millions (FPKM) method. The DESeq2 R package v.1.16.1 was used for differential expression analysis of three biological replicates per condition. The Benjamini and Hochberg's approach was applied to calculate $P$-values and expression fold change (FC), and genes with $P$-values $<0.05$ and FC $>2$ were considered differentially expressed. DEGs were functionally annotated using Blast2GO at http://www.blast2go.de [31] and assessed for enrichment using the clusterProfiler $\mathrm{R}$ package. The Kyoto Encyclopedia of Genes and Genomes (KEGG) database was used for DEG pathway annotation and enrichment analysis (http://www.genome.jp/kegg/).

\section{Verification of RNA sequencing data}

The gene encoding S. japonicum NADH-ubiquinone reductase was employed as an endogenous reference gene [18]. The primer sequences used for qPCR were designed using Primer Express v.3.0 software (Applied Biosystems, Foster City, CA, USA) and are listed in Table 1. qPCR amplification was performed using a SYBR green kit (TaKaRa, Dalian, China) and an ABI 7500 Realtime System (Life Technologies). The qPCR cycling conditions were as follows: $95^{\circ} \mathrm{C}$ for $3 \mathrm{~min}$, followed by 40 cycles of $95^{\circ} \mathrm{C}$ for $30 \mathrm{~s}, 56^{\circ} \mathrm{C}$ for $30 \mathrm{~s}$ and $72{ }^{\circ} \mathrm{C}$ for $2 \mathrm{~min}$. Melt curve analysis from 72 to $95^{\circ} \mathrm{C}$ was performed to ensure a specific product was amplified in each reaction. The relative expression level of the genes was calculated using the $2^{-\Delta \Delta \mathrm{CT}}$ method [32].

\section{Results}

\section{Morphological differences between parasites} from re-infected and primary-infected water buffaloes

Lengths of male and female worms were reported in our previous publication [23]. Here we analyzed other morphological characteristics and present the results from 30 pairs of worms (30 male and 30 female) in Table 2 . Organs, including the oral sucker, ventral sucker and ovaries, of male and female worms from re-infected water buffaloes were smaller than those of worms from primary-infected animals. The differences were significant
Table 1 Primers used in quantitative PCR

\begin{tabular}{|c|c|c|}
\hline Primer name & Sequence $\left(5^{\prime}-3^{\prime}\right)$ & Product size (bp) \\
\hline \multicolumn{3}{|c|}{ Upregulated genes } \\
\hline Sjp_0125630F & CATGGATCTGTGCTCGCGTA & 150 \\
\hline Sjp_0125630R & GCAAACCCGTGATTGGCAAG & \\
\hline Novel03105F & GAGCAGACCGCTTCGATGTA & 75 \\
\hline Novel03105R & CCGAATTTCGCTTGCCAGTC & \\
\hline Novel00129F & ACTTCCCGCTCAAGATCACC & 103 \\
\hline Novel00129R & ACTCGTAAGAGTGGGGTCCA & \\
\hline Novel01404F & TTCTCAACAGCGTACACCCC & 77 \\
\hline Novel01404R & GACCCAGTAGTGCAGACGTT & \\
\hline Novel02684F & GGACGCCAGGTTAAGGAAGA & 93 \\
\hline Novel02684R & TCTACCAGCCGAAGGAGTGT & \\
\hline \multicolumn{3}{|c|}{ Downregulated genes } \\
\hline Novel01481F & TTGGCCTCAATCGATCCTATCT & 136 \\
\hline Novel01481R & CTGTGATTGCTTACCGTTTTGC & \\
\hline Novel00143F & TGTGGGATTAAGGCCTACCA & 95 \\
\hline Novel00143R & GCGAACGTAGAACAACTGCC & \\
\hline Novel02333F & $\begin{array}{l}\text { CGTTGTATGTGGATCATT } \\
\text { TGTGC }\end{array}$ & 70 \\
\hline Novel02333R & $\begin{array}{l}\text { TTCATCTTTGCATTCACTACT } \\
\text { ACAC }\end{array}$ & \\
\hline Sjp_0116000F & TGCAATTGTTCACCGTGATG & 86 \\
\hline Sjp_0116000R & TGTCTCTGCAACATCTTGTGAT & \\
\hline Novel00935F & CGCAATCAGATGTTCAGGGT & 105 \\
\hline Novel00935R & TCGGAAACCCAATGTCTGGAT & \\
\hline
\end{tabular}

Table 2 Morphometry of S. japonicum worms recovered from primary-infected and re-infected water buffaloes

\begin{tabular}{lll}
\hline Characters & Primary infection & Re-infection \\
\hline Male worms & $(n=15)$ & $(n=15)$ \\
Oral sucker length & $261 \pm 74$ & $245 \pm 23$ \\
Oral sucker width & $176 \pm 34$ & $170 \pm 23$ \\
Ventral sucker length & $328 \pm 13$ & $273 \pm 8^{*}$ \\
Ventral sucker width & $236 \pm 46$ & $193 \pm 24$ \\
Female worms & $(n=15)$ & $(n=15)$ \\
Oral sucker length & $44 \pm 3$ & $33 \pm 5^{*}$ \\
Oral sucker width & $34 \pm 1$ & $24 \pm 7$ \\
Ventral sucker length & $109 \pm 8$ & $94 \pm 4$ \\
Ventral sucker width & $87 \pm 8$ & $73 \pm 3$ \\
Ovary length & $578 \pm 23$ & $297 \pm 27^{*}$ \\
Ovary width & $150 \pm 8$ & $104 \pm 9^{*}$ \\
No. of eggs in utero & $41 \pm 2$ & $12 \pm 1^{*}$ \\
\hline
\end{tabular}

Note: Data are presented as the mean \pm standard deviation; length and width in $\mu \mathrm{m}$

*P $P<0.05$

for the length of the ventral sucker in males $(328 \pm 13$ vs $\left.273 \pm 8 \mu \mathrm{m} ; t_{(14)}=26.63, P=0.02\right)$, the length of the oral sucker in females $\left(44 \pm 3 v s 33 \pm 5 \mu \mathrm{m} ; t_{(14)}=8.52\right.$, 
$P=0.02)$ and the length $(578 \pm 23$ vs $297 \pm 27 \mu \mathrm{m}$; $\left.t_{(14)}=40.31, P=0.005\right)$ and width $(150 \pm 8 v s 104 \pm 9 \mu \mathrm{m}$; $\left.t_{(14)}=19.80, P=0.02\right)$ of the ovary, but no other significant differences were found. We also observed that there were significantly fewer eggs in the uteri of female worms $\left(41 \pm 2 v s 12 \pm 1 ; t_{(14)}=56.16, P<0.0001\right)$ from re-infected water buffaloes.

\section{RNA extraction and RNA-Seq}

The six RNA samples, including three from worms recovered from primary-infected water buffaloes and three from worms recovered from re-infected water buffaloes, had prominent $18 S$ and $28 S$ ribosomal peaks on agarose gels (data not shown). According to Bioanalyzer 2100 analysis, the RINs of all samples were $>7.0$. These results showed that all RNA samples possessed high integrity and purity and could be used for further experiments.

cDNA was generated and sequenced using an Illumina sequencing platform. Q30 was $>90 \%$ for each sample. After removing adaptors and low-quality reads, we obtained approximately $305,888,154$ high quality reads in all samples. The average mapping rate of clean reads $(51,832,023$ reads per sample) to $S$. japonicum genomic data in two independent analyses was 79.545\% (Table 3). The correlation coefficient of the transcriptional profiles between three biological replicates of the six samples was 0.969-0.985 (Fig. 2).

We identified a total of 16,605 genes, including 3867 novel genes. Of these, 13,310 genes were expressed in adult worms recovered from both primary-infected and re-infected water buffaloes; 256 were only expressed in adult worms recovered from re-infected water buffaloes and 219 were only expressed in adult worms recovered from primary-infected water buffaloes (Fig. 3a). Using a $P$-value cutoff of $<0.05$ and an FC cutoff of $>2,112$ genes were identified as DEGs (Fig. 3b). Compared with worms recovered from primary-infected water buffaloes, 51 genes were upregulated and 61 genes were downregulated in worms recovered from re-infected water buffaloes (Fig. 3b). DEGs that were successfully mapped to homologous proteins in the Gene DB database (http:// www.genedb.org/Homepage) or annotated using the Swiss-Prot database (http://www.gpmaw.com/html/swiss -prot.html) are listed in Tables 4 and 5. Only genes that were successfully annotated using the Swiss-Prot database or found to have homologous proteins in the Gene DB database are listed. Cluster analysis for these DEGs in all six samples is shown in Fig. 3c.

\section{GO and KEGG enrichment analysis of differentially expressed genes}

To obtain a better understanding of the enriched functions of DEGs, GO term enrichment analysis was performed. Of all identified genes, a total of 9012 (65.37\%) were annotated (Additional file 1: Table S1). A total of $127 \mathrm{GO}$ terms were enriched with $P<0.05$ (Additional file 2: Table S2). Annotations of DEGs from the SwissProt database are listed in Tables 4 and 5.

Of the upregulated genes in worms recovered from reinfected water buffaloes, $110 \mathrm{GO}$ terms were significantly enriched with $P<0.05$ (Fig. 4, Additional file 3: Table S3). Specifically, 83 GO terms, such as "metabolic process", "cellular metabolic process", "nitrogen compound metabolic process" and "cellular biosynthetic process", were overrepresented in the "biological process" category; $24 \mathrm{GO}$ terms, including "hydrogen ion transmembrane

Table 3 Information on sequencing and mapping of reads to genomic data

\begin{tabular}{|c|c|c|c|c|c|c|}
\hline Sample name & $\mathrm{C} 1$ & C2 & $\mathrm{C} 3$ & $\mathrm{~T} 1$ & $\mathrm{~T} 2$ & $\mathrm{~T} 3$ \\
\hline Total reads ${ }^{a}$ & $62,194,716$ & $51,418,256$ & $39,854,922$ & $42,581,418$ & $57,908,184$ & $51,930,658$ \\
\hline Total mapped (\%) & 49,530,227 (79.64) & $40,967,457(79.67)$ & $31,302,966(78.54)$ & $33,901,809(79.62)$ & $46,380,422(80.09)$ & $41,394,770(79.71)$ \\
\hline Multiple mapped (\%) & $1,634,122(2.63)$ & $1,263,823(2.46)$ & $1,009,725(2.53)$ & $1,110,332(2.61)$ & $1,478,461(2.55)$ & $1,404,997(2.71)$ \\
\hline Uniquely mapped (\%) ${ }^{d}$ & $47,896,105$ (77.01) & $39,703,634(77.22)$ & $30,293,241(76.01)$ & $32,791,477(77.01)$ & $44,901,961(77.54)$ & $39,989,773(77.01)$ \\
\hline Read-1 (\%) & $24,189,990$ (38.89) & $20,074,308(39.04)$ & $15,311,530(38.42)$ & $16,478,614(38.7)$ & $22,663,081$ (39.14) & $20,193,218(38.88)$ \\
\hline Read-2 (\%) & $23,706,115$ (38.12) & $19,629,326(38.18)$ & $14,981,711$ (37.59) & $16,312,863(38.31)$ & $22,238,880(38.4)$ & $19,796,555(38.12)$ \\
\hline Reads map to '+' $(\%)^{\mathrm{e}}$ & $23,840,204$ (38.33) & $19,786,847(38.48)$ & $15,100,441$ (37.89) & $16,352,368(38.4)$ & $22,390,777$ (38.67) & $19,940,268(38.4)$ \\
\hline Reads map to '-' (\%) ${ }^{f}$ & $24,055,901$ (38.68) & $19,916,787(38.73)$ & $15,192,800(38.12)$ & $16,439,109(38.61)$ & $22,511,184(38.87)$ & $20,049,505(38.61)$ \\
\hline
\end{tabular}

\footnotetext{
a Sampling sequence filtered by sequencing data (clean data)

b Statistics on the number of sequencing sequences that can be mapped to the genome and the number in parentheses indicates the number of sequences (total mapped reads) as a percentage (\%) of clean reads

c Quantitative statistics of sequencing sequences with multiple alignment positions on the reference sequence

${ }^{d}$ Quantitative statistics of sequencing sequences with unique alignment positions on the reference sequence

e The statistics of the sequencing sequence alignment to the positive strands on the genome

${ }^{f}$ The statistics of the sequencing sequences aligned to the negative strands on the genome
} 


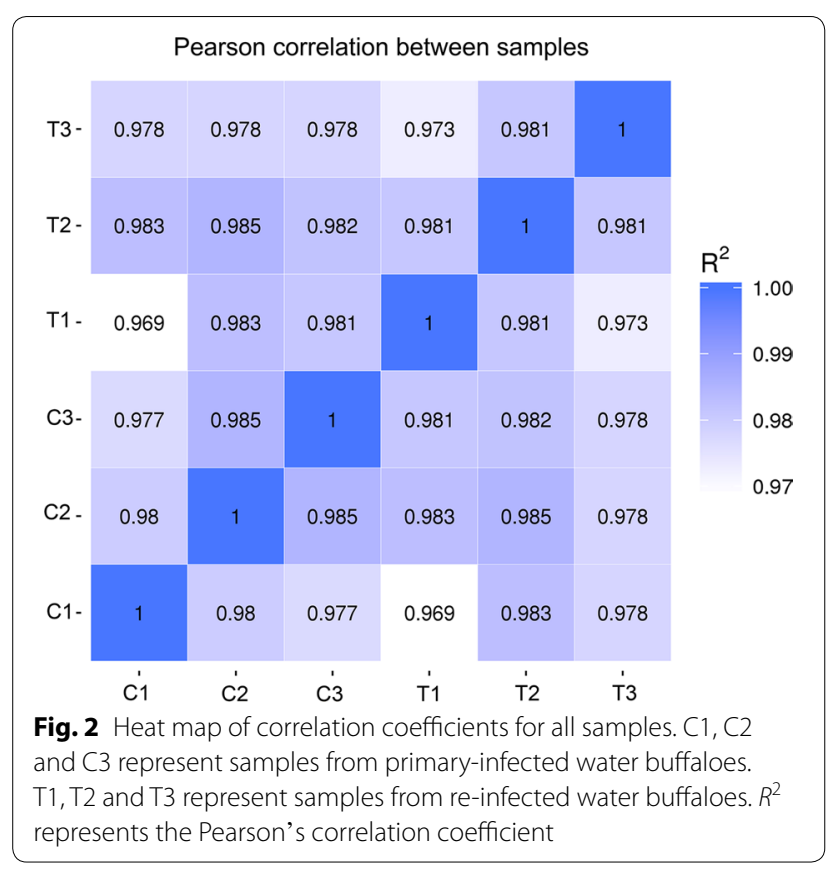

transporter activity", "monovalent inorganic cation transmembrane transporter activity", "inorganic cation transmembrane transporter activity" and "cation transmembrane transporter activity", were overrepresented in the "molecular function" category; and three GO terms, including "viral procapsid", "Cdc73/Paf1 complex" and "transcription elongation factor complex", were overrepresented in the "cellular component" category.

Of the downregulated genes in worms recovered from re-infected water buffaloes, a total of $35 \mathrm{GO}$ terms were significantly enriched with $P<0.05$ (Fig. 4, Additional file 4: Table S4). In the "biological process" category, 11 GO terms, including "oxidation-reduction process", "monovalent inorganic cation transport" and "response to ionizing radiation", were significantly enriched; 19 GO terms, such as "transmembrane transporter activity", "calcium-dependent phospholipid binding" and "phospholipid binding", were significantly enriched in the "molecular function" category; and five GO terms, such as "photosystem I reaction center", "transcription factor TFIID complex" and "exocyst", were significantly enriched in the "cellular component" category.

Functional enrichment analyses of GO terms of DEGs were compared between the upregulated and downregulated genes in worms recovered from re-infected water buffaloes (Fig. 4, Table 6). Only DEGs that were successfully annotated using the Swiss-Prot database are listed. The analysis indicated that a large number of GO terms associated with metabolic processes and biosynthesis were enriched only in the upregulated genes. By contrast, the GO term oxidation-reduction was enriched only in downregulated genes. GO terms related to transportation and binding were significantly enriched in both the upregulated and downregulated genes. However, we found that upregulated and downregulated genes were associated with different binding functions. Upregulated genes were related to iron ion binding, heme binding and tetrapyrrole binding, whereas the downregulated genes were related to calcium-dependent phospholipid binding, lipid binding and calcium ion binding.

KEGG pathway enrichment analysis of DEGs indicated that both upregulated and downregulated genes were involved in oxidative phosphorylation and metabolic pathways. In addition, upregulated genes were also involved in extracellular matrix-receptor interactions, $\mathrm{N}$-glycan biosynthesis and ribosome biogenesis in eukaryotes, and downregulated genes were associated with arginine and proline metabolism, biosynthesis of amino acids and spliceosome (Fig. 5, Additional file 5: Table S5).

\section{qPCR validation of RNA sequencing data}

To validate RNA-Seq data, qPCR was performed for 10 genes with different biological functions and expression patterns, including five upregulated genes and five downregulated genes, using NADPH as the housekeeping gene for internal normalization. The qPCR results corresponded with the RNA-Seq data (Fig. 6a), with a significant correlation coefficient of $0.9405(P<0.0001, n=10)$ (Fig. 6b).

\section{Discussion}

Intriguingly, water buffaloes are less susceptible to $S$. japonicum infection than yellow cattle, goats and rabbits [33] and self-curing has been observed in water buffaloes after infection [21]. In our previous publication, we reported a reduction in worm burdens of over $97.4 \%$ $(P<0.05)$ in re-infected compared to primary-infected water buffaloes [23]. Additionally, surviving adult female worms in water buffaloes previously exposed to S. japonicum were shorter in length. Here we further observed that organs including the oral sucker, ventral sucker and ovaries of both male and female worms were smaller in re-infected buffaloes than in primary-infected buffaloes, with a significant difference $(P<0.05)$ observed in the length of the ventral sucker of males, the length of the oral sucker of females and the length and width of the ovary. We also observed that there were significantly fewer eggs in the uteri of female worms of re-infected water buffaloes $(P<0.05)$. These results revealed that worm development was inhibited in water buffaloes previously exposed to $S$. japonicum. The susceptibility varies among diverse mammalian hosts to $S$. japonicum infection and the development of the worms in these hosts 


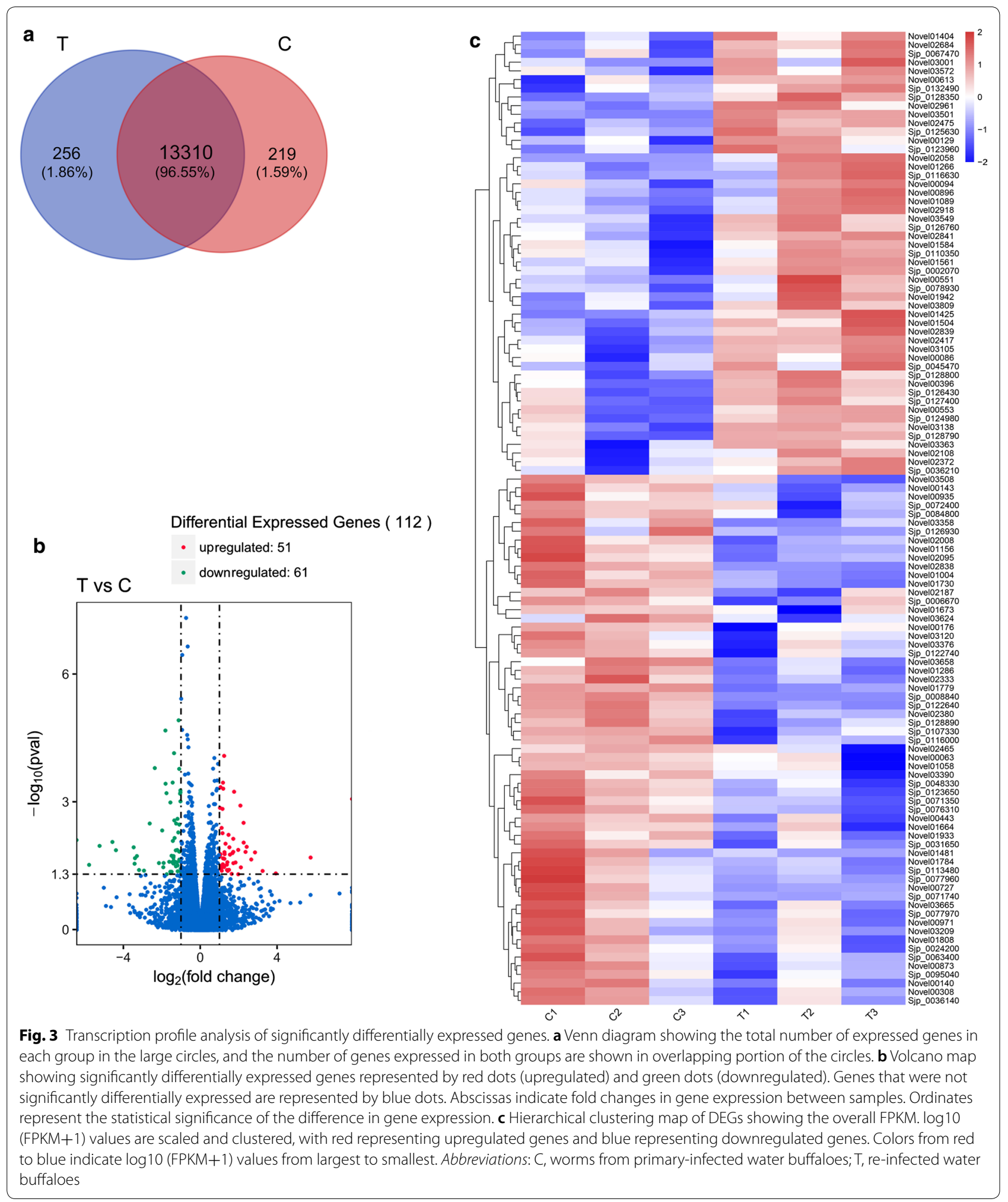

is different; for example, in susceptible hosts the development of the worm is favorable and in less susceptible hosts it is repressed [3, 20,34, 35]. The growth environment of the worm in re-infected buffalo may be similar to that in an unsuitable host. Therefore, the worm development may be inhibited in the host environment.

Due to variations in the susceptibility of disparate mammalian hosts to $S$. japonicum infection, several 
Table 4 Upregulated genes in schistosomes recovered from re-infected water buffaloes normalized to primary-infected water buffaloes

\begin{tabular}{|c|c|c|c|}
\hline Gene_ID & Protein homology & Annotation & Fold Change \\
\hline Novel02058 & Reverse transcriptase SjR1 & na & na \\
\hline Sjp_0123960 & Immunogenic miracidial antigen 81 & na & 15.20106 \\
\hline Sjp_0125630 & Uncharacterized protein & Virion assembly & 9.447286 \\
\hline Novel00553 & Magnesium transporter nipa & Magnesium ion transmembrane transporter activity & 6.277108 \\
\hline Novel01404 & Protein TraX & Integral component of membrane & 5.105315 \\
\hline Novel03501 & $\begin{array}{l}\text { Channel-forming transporter/TpsB family cytolysins activa- } \\
\text { tor }\end{array}$ & Protein transport & 4.772681 \\
\hline Novel02684 & Uncharacterized protein LOC106012791 & Zinc ion binding & 4.759467 \\
\hline Novel02475 & Gag-Pol polyprotein & Threonine kinase & 4.240105 \\
\hline Sjp_0110350 & Asparagine-rich protein & na & 3.560797 \\
\hline Sjp_0124980 & SJCHGC04245 protein & Heterocyclic compound binding & 3.293907 \\
\hline Sjp_0078930 & Centrosomal protein of $162 \mathrm{kDa}$ & Bacteriocin immunity, toxic substance binding & 3.189433 \\
\hline Sjp_0132490 & Retinol dehydrogenase 12 & Catalytic activity & 3.096417 \\
\hline Novel00396 & Reverse transcriptase & Intrinsic component of membrane & 2.91319 \\
\hline Novel02372 & Polyprotein & DNA binding & 2.854029 \\
\hline Sjp_0067470 & Trehalose-6-phosphate hydrolase & Cation binding & 2.620605 \\
\hline Novel03138 & Ribonuclease III, putative & na & 2.601241 \\
\hline Novel01504 & SJCHGC02001 protein & Integral component of membrane & 2.403939 \\
\hline Sjp_0002070 & $\begin{array}{l}\text { Malignant fibrous histiocytoma-amplified sequence } 1 \\
\text { homolog }\end{array}$ & Purine nucleotide binding & 2.379569 \\
\hline Sjp_0126430 & ATP synthase subunit a & Purine nucleoside monophosphate biosynthetic process & 2.360512 \\
\hline Sjp_0128790 & Cytochrome c oxidase subunit 1 & Oxidoreductase activity & 2.287703 \\
\hline Sjp_0128350 & Periodic tryptophan protein 2 homolog & na & 2.270484 \\
\hline Novel02961 & TPA: endonuclease-reverse transcriptase & Transferase activity & 2.251209 \\
\hline Sjp_0127400 & Cytochrome $c$ oxidase subunits $1+2$ & $\begin{array}{l}\text { Generation of precursor metabolites and energy, } \\
\text { cytochrome-c oxidase activity }\end{array}$ & 2.228696 \\
\hline Novel00551 & Centrosomal protein of $162 \mathrm{kDa}$ & Serine-type carboxypeptidase activity & 2.226072 \\
\hline Sjp_0036210 & Glycoprotein 3-alpha---fucosyltransferase A & Acting on L-amino acid peptides & 2.111693 \\
\hline Sjp_0128800 & ATP synthase subunit a & Purine nucleoside triphosphate biosynthetic & 2.076854 \\
\hline Novel00613 & Hypothetical protein MS3_03474 & Porphobilinogen synthase activity & 2.068952 \\
\hline Novel03809 & Reverse transcriptase & $\begin{array}{l}\text { RNA-directed DNA polymerase activity, nucleic acid bind- } \\
\text { ing }\end{array}$ & 2.067948 \\
\hline Novel03549 & TPA: endonuclease-reverse transcriptase & na & 2.033408 \\
\hline Sjp_0126760 & Glutamic acid-rich protein & Nucleobase-containing compound biosynthetic process & 2.021043 \\
\hline
\end{tabular}

Notes: Only genes that were successfully annotated using the Swiss-Prot database or found to have homologous proteins in the Gene DB database are listed Abbreviation: na, not available

recent comparative studies using proteomic analysis [36] and microarray analysis [19, 37] of S. japonicum from different hosts have been conducted, and numerous DEGs that may influence parasite survival and development have been identified. Yang et al. [19] compared the transcriptional profiles of adult schistosome worms recovered from yellow cattle and water buffaloes and found that several genes involved in transcription, transport, lipid metabolism, energy metabolism, nucleotides and energy and signaling pathways were differentially expressed in worms from these two hosts. In the present study, we compared the gene expression profiles of adult worms recovered from re-infected and primaryinfected water buffaloes using RNA-Seq. We identified 112 DEGs in worms recovered from re-infected water buffaloes, including 61 upregulated genes and 51 downregulated genes. Genes related to transport, binding and oxidation-reduction were downregulated in adult worms from re-infected water buffaloes. For example, the GO terms "calcium-dependent phospholipid binding" (Sjp_0113480, Sjp_0077960, Sjp_0077970), "lipid binding" (Sjp_0113480, Sjp_0077960, Sjp_0077970) and "calcium ion binding" (Sjp_0077970, Sjp_0113480, Sjp_0077960) were enriched only in downregulated 
Table 5 Downregulated genes in schistosomes recovered from re-infected water buffaloes normalized to primary-infected water buffaloes

\begin{tabular}{|c|c|c|c|}
\hline Gene_ID & Protein homology & Annotation & Fold change \\
\hline Sjp_0008840 & na & Integral component of membrane & na \\
\hline Sjp_0126930 & SJCHGC00271 protein & Transmembrane & 0.0264 \\
\hline Novel00143 & Uncharacterized protein & Mitochondrion & 0.090296 \\
\hline Novel02333 & $\begin{array}{l}\text { Zinc finger and BTB domain-containing protein } 16 \text { (Fundulus hetero- } \\
\text { clitus (killifish; mummichog)) }\end{array}$ & Integral component of membrane & 0.09335 \\
\hline Sjp_0071350 & Egg protein P3811 & Transmembrane & 0.09468 \\
\hline Novel00935 & Egg protein CP11 (Schistosoma japonicum) & na & 0.109659 \\
\hline Novel03624 & Putative membrane protein & Transmembrane & 0.131051 \\
\hline Novel00443 & Transcriptional regulator & Regulation of transcription, DNA-templated & 0.161175 \\
\hline Sjp_0048330 & $\begin{array}{l}\text { Beta-1,3-galactosyl-O-glycosyl-glycoprotein beta-1,6-N-acetylglu- } \\
\text { cosaminyltransferase } 3\end{array}$ & Transferase activity & 0.224891 \\
\hline Novel01156 & Uncharacterized protein, SJCHGC08959 protein & Establishment of localization & 0.262939 \\
\hline Sjp_0123650 & $\begin{array}{l}\text { CAP-Gly domain-containing linker protein 2, gene } \\
\text { name:MS3_05295 }\end{array}$ & Response to abiotic stimulus & 0.266222 \\
\hline Sjp_0128890 & Cytochrome c oxidase subunit 2 & Aerobic respiration & 0.295064 \\
\hline Novel02380 & Gap-Pol polyprotein & na & 0.297261 \\
\hline Novel02465 & Reverse transcriptase & na & 0.3384 \\
\hline Novel00176 & SJCHGC04823 protein & na & 0.339669 \\
\hline Sjp_0072400 & Uncharacterized protein & Transmembrane & 0.34707 \\
\hline Sjp_0031650 & Probable delta-1-pyrroline-5-carboxylate synthase & Oxidoreductase activity & 0.363745 \\
\hline Novel00063 & Transposon Ty3-G Gag-Pol polyprotein & na & 0.368695 \\
\hline Sjp_0113480 & Annexin A3 & Secretion by cell & 0.371285 \\
\hline Sjp_0107330 & Uncharacterized protein & Transmembrane & 0.373661 \\
\hline Novel01784 & Uncharacterized protein, HYPBUDRAFT_236782 & Cytoskeleton & 0.380482 \\
\hline Sjp_0095040 & Amide-activated amiloride-sensitive sodium channel & Sodium ion transmembrane transporter activity & 0.380508 \\
\hline Sjp_0084800 & Beta-catenin-like protein 1 & na & 0.391179 \\
\hline Novel01664 & Gag-Pol polyprotein & na & 0.39513 \\
\hline Sjp_0122740 & Annexin & na & 0.414344 \\
\hline Novel03120 & Hypothetical protein N336_01965, partial (Phalacrocorax carbo) & na & 0.418181 \\
\hline Novel00971 & Hypothetical protein Smp_144270 (Schistosoma mansoni) & na & 0.431371 \\
\hline Novel01286 & Uncharacterized protein & Transmembrane & 0.434793 \\
\hline Sjp_0077960 & Annexin A10 & na & 0.439215 \\
\hline Sjp_0122640 & NADH-ubiquinone oxidoreductase chain 1 & Inorganic cation transmembrane transporter activity & 0.457011 \\
\hline Novel02095 & Mitogen-activated protein kinase 15 & na & 0.467131 \\
\hline Sjp_0077970 & Annexin A3 & Phospholipase activity & 0.468623 \\
\hline Novel01808 & Hypothetical protein Smp_153120 & na & 0.472374 \\
\hline Novel02008 & Reverse transcriptase & na & 0.481698 \\
\hline Novel03665 & Putative glycosyltransferase, partial & na & 0.487137 \\
\hline Sjp_0071740 & Uncharacterized protein & Transmembrane & 0.487779 \\
\hline Novel03376 & Hypothetical protein M959_01698, partial & Photosystem I reaction center & 0.488354 \\
\hline Sjp_0076310 & Tight junction protein ZO-1 & Transcription factor TFIID complex & 0.49107 \\
\hline Novel00873 & Hypothetical protein MS3_01562 & NADH dehydrogenase (ubiquinone) activity & 0.496237 \\
\hline
\end{tabular}

Notes: Only genes that were successfully annotated using the Swiss-Prot database or found to have homologous proteins in the Gene DB database are listed Abbreviation: na, not available

genes. Schistosoma japonicum parasites are unable to synthesize some key nutrient molecules such as fatty acids, sterols, purines and nine essential amino acids, including arginine and tyrosine [38]. Previous reports suggested that schistosomes cannot produce long-chain fatty acids and only obtain complex lipids for the synthesis of sterols and fatty acids from the host [39]. We hypothesize that the downregulation of these genes 
a

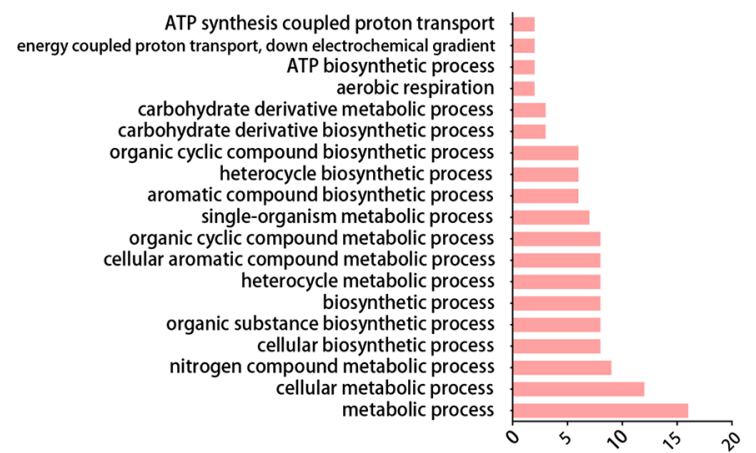

b

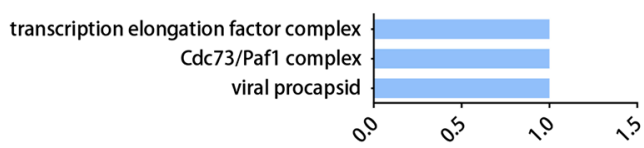

C

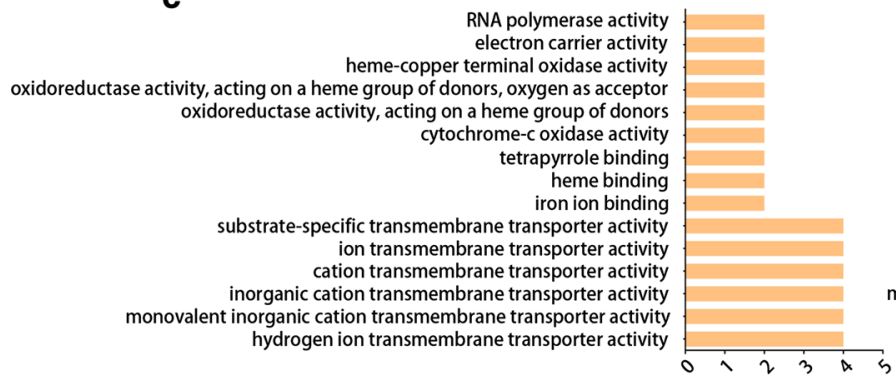

d

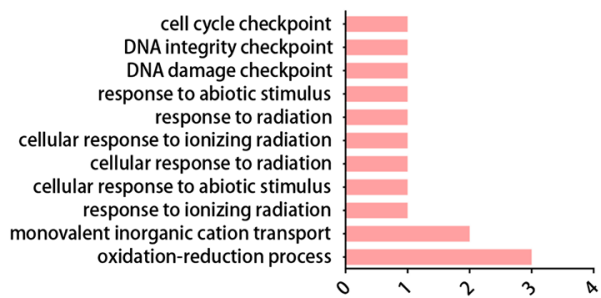

e

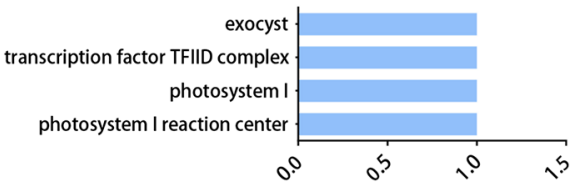

f

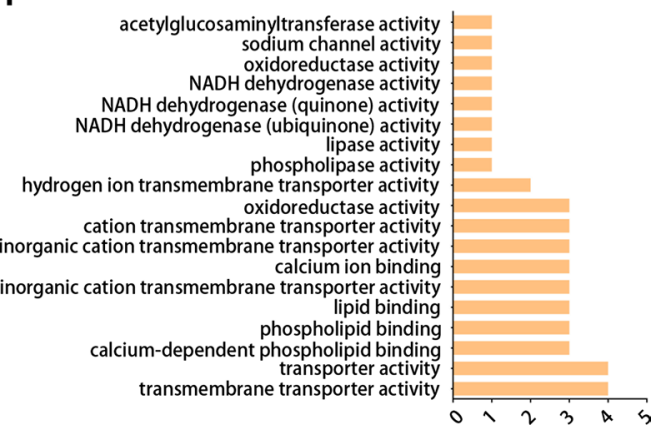

Fig. $4 \mathrm{GO}$ enrichment analysis of differentially expressed genes. a-c Upregulated genes. $\mathbf{d}$-f Downregulated genes. GO terms were categorized as biological processes $(\mathbf{a}, \mathbf{d})$, cellular components $(\mathbf{b}, \mathbf{e})$ or molecular functions $(\mathbf{c}, \mathbf{f})$ using the Blast2Go program. Genes with no assigned GO terms were excluded from the graph. The ordinate shows the enriched GO term, and the abscissa shows the number of differentially expressed genes associated with the term

contributed to the reduction in worm numbers and the maldevelopment of surviving worms in re-infected water buffaloes by mechanisms other than acquired immunity [23]. Our functional enrichment analyses indicated that a large number of GO terms enriched in the upregulated genes were associated with metabolic processes and biosynthesis. In addition, we observed the overexpression of genes with a variety of binding-related activities, such as "zinc ion binding" (uncharacterized protein LOC106012791), "heterocyclic compound binding" (SJCHGC04245 protein), "DNA binding" (polyprotein), "cation binding" (trehalose-6-phosphate hydrolase), "purine nucleotide binding" (malignant fibrous histiocytoma-amplified sequence 1 homolog) and "nucleic acid binding" (reverse transcriptase). We speculated that the overexpression of genes related to metabolic processes and biosynthesis in surviving worms recovered from re-infected water buffaloes might be a compensatory mechanism by these worms to adapt to disadvantageous environments. Compensation mechanisms have been extensively studied in many diseases of humans and animals, such as Parkinson's disease [40], facet joints arthritis [41] and unilateral kidney pathology[42]. In addition, synaptic plasticity deficit studies of Alzheimer's disease have shown that the recruitment of nitric oxide (NO) serves a compensatory role to boost synaptic transmission and plasticity during early AD stages[43]. Presumably, in order to cope with the host's unfavorable host environment, re-infected buffalo-derived worms employ a compensatory mechanism to integrate some molecules involved in metabolism and synthesis. Our results are consistent with the biology of S. japonicum and will help to clarify the basic molecular mechanisms underlying resistance to re-infection in water buffaloes, which might provide new insight into the genes functionally related to development as well as aid in screening of anti-schistosome drug targets and vaccine candidates. 


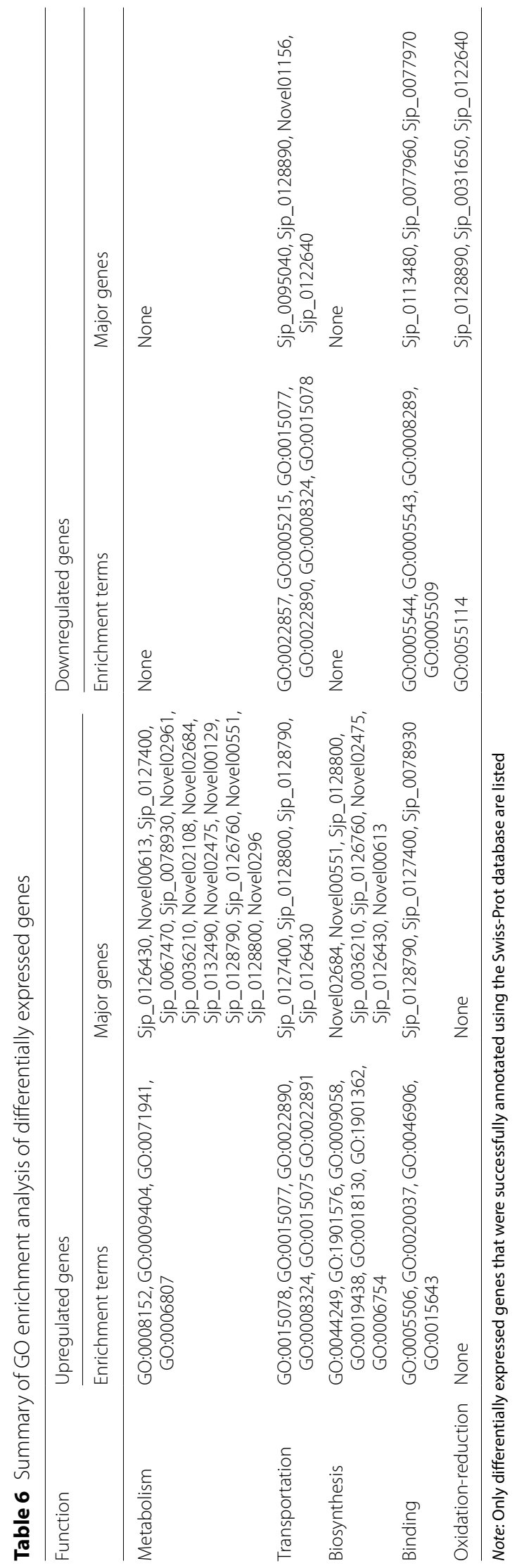



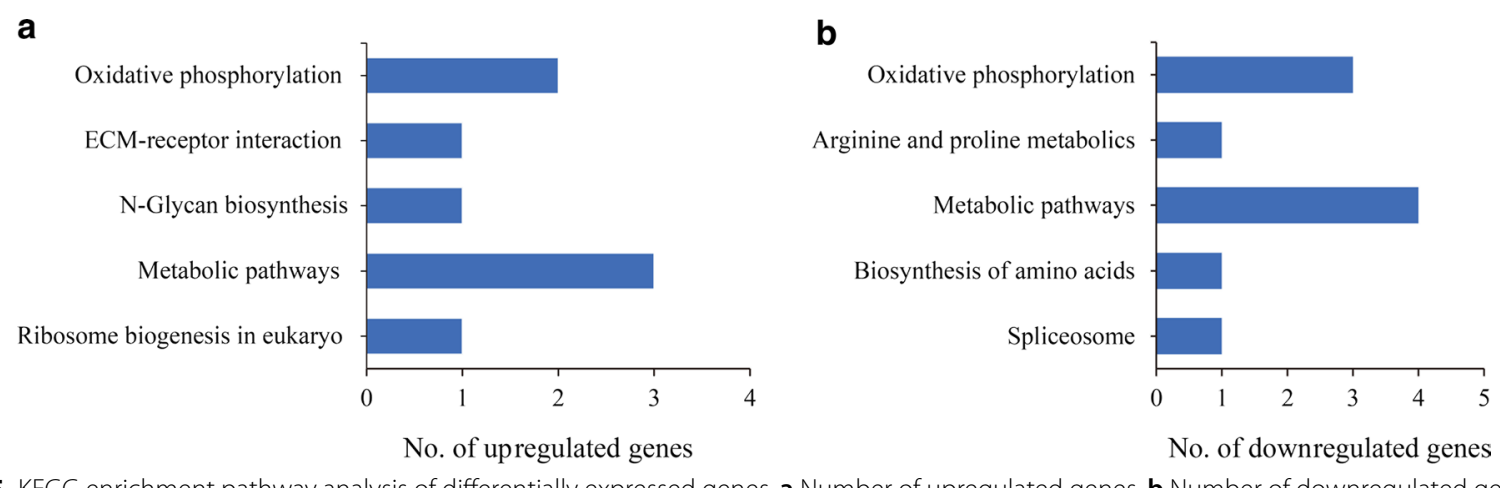

No. of downregulated genes

Fig. 5 KEGG enrichment pathway analysis of differentially expressed genes. a Number of upregulated genes. $\mathbf{b}$ Number of downregulated genes

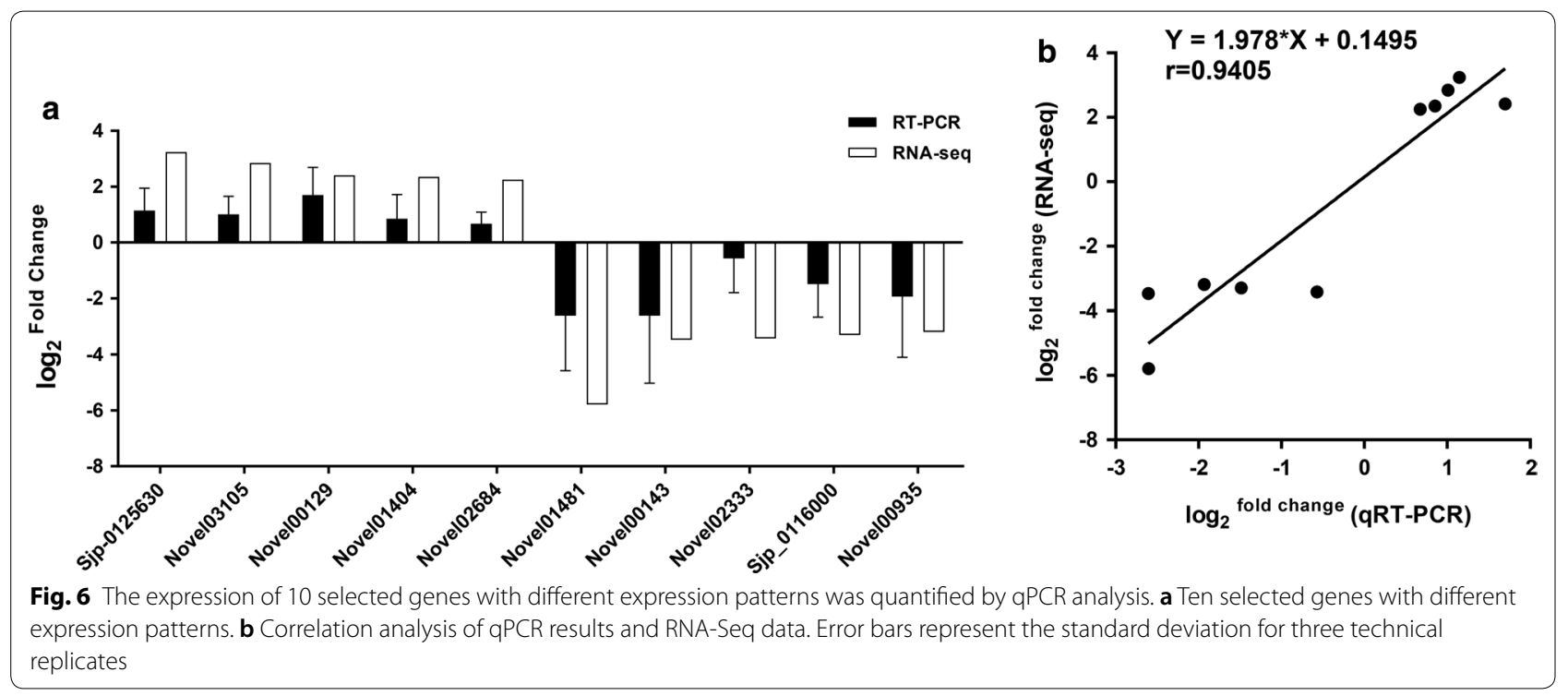

Among the 112 DEGs, we observed that the transcript Sjp_0008840 was not expressed and that the transcript Novel02058 was expressed only in worms recovered from re-infected buffaloes. According to GO annotation analysis, transcript Sjp_0008840 is an integral membrane component. The transcript Novel02058 has 73.3\% similarity at the gene level with reverse transcriptase SjR1 in S. japonicum [44] and, according to the UniProt database, functions in anaerobic aromatic compound degradation. We also found that the gene (Sjp_0078930) encoding toxic substance binding protein (centrosomal protein of $162 \mathrm{kDa}$ ) was upregulated in worms recovered from re-infected buffaloes. According to GO functional enrichment analysis, this centrosomal protein of 162 $\mathrm{kDa}$ is a critical molecule in centriole duplication during cell proliferation and development. Gudi et al. [45] showed that accurate centriole duplication is important for many cellular and physiological activities such as cell division and ciliogenesis. According to gene functional annotation analysis using the Gene DB database (http:// www.genedb.org) [46], the gene is the DNA doublestrand break repair protein RAD50 ATPase. DNA double-strand breaks are induced by environmental agents such as ionizing radiation and genotoxic chemicals and occurring spontaneously during DNA replication, threatening genomic stability [47]. DNA damage repair is fundamental to cell survival and cancer prevention [47, 48]. Thus, the effect of differential expression of these three genes on schistosome development is worthy of further investigation.

Reactive oxygen species (ROS) are naturally produced in cell compartments such as the peroxisome and mitochondria as well as at the plasma membrane and play key roles in signaling cell fate, growth and survival [49]. The observed increase in hydrogen peroxide $\left(\mathrm{H}_{2} \mathrm{O}_{2}\right)$ detoxification capacity and resistance to multiple sources of ROS during S. mansoni development in the vertebrate host suggested that adult parasites are exposed to greater 
redox challenges than immature parasites [50,51]. Similarly, we speculate that redox challenges in re-infected water buffaloes are greater than in primary-infected animals. Cytochrome c oxidase $(\mathrm{CcO})$, which is a highly regulated enzyme, is believed to regulate mitochondrial oxidative metabolism and ATP synthesis [52, 53]. A previous study suggested that $\mathrm{CcO}$ dysfunction is associated with increased mitochondrial ROS production and cellular toxicity. Under normal physiological conditions, $\mathrm{CcO}$ is rate-limiting in the respiratory chain and its activity is an indicator of the oxidative capacity of cells [53]. Previous work indicated that the survival mechanisms of schistosomes in their definitive hosts included the production of protective antioxidant proteins, which neutralized oxidative damage caused by the host immune response as well as by worm-generated oxygen radicals $[54,55]$. Oliveira et al. [49] found that S. mansoni employed a unique antioxidant network that is key to parasite survival and may be a valuable chemotherapeutic target. In the present study, three genes (Sjp_0128890, Sjp_0031650 and Sjp_0122640) related to oxidation-reduction processes were downregulated in worms recovered from re-infected water buffaloes, whereas the opposite expression pattern was observed for genes (Sjp_0127400 and Sjp_0128790) related to the redox pathway, including genes related to cytochrome $\mathrm{c}$ oxidase subunit 1 and cytochrome $c$ oxidase subunit $1+2$. These results indicate that redox reactions and ROS produced by circulating immune cells might play an essential role in parasite killing. Therefore, surviving worms have an increased ability to detoxify ROS and avoid redox imbalances and parasite cell death triggered by the host immune system.

Compared with cattle, fewer parasites are able to survive and mature in water buffaloes. The upregulation of elongase of very long-chain fatty acids (ELOVL) in adult schistosomes from water buffaloes might be a compensatory mechanism by parasites in less susceptible hosts to enable worm growth and development [56]. Here we found that genes related to metabolism and biosynthesis were upregulated in surviving worms in re-infected water buffaloes, which might be another compensatory mechanism by parasites in re-infected or immunized animals. Regarding metabolism, GO terms enriched in upregulated genes included metabolic processes, nitrogen compound metabolic processes, heterocycle metabolic processes, organic cyclic compound metabolic processes and carbohydrate derivative metabolic processes. Importantly, we found that three genes (Sjp_0067470, Sjp_0036210 and Sjp_0128800) were associated with most of these metabolic processes. For biosynthesis, GO terms enriched in upregulated genes included cellular biosynthetic processes, chemical component (i.e. organic substances, aromatic compounds, heterocycle and organic cyclic compounds) biosynthetic processes, energy substance (i.e. carbohydrate derivatives, ATP, purine nucleoside monophosphate, purine ribonucleoside monophosphate, nucleoside triphosphate and purine nucleoside triphosphate) biosynthetic processes and glycosyl compound biosynthetic processes. In particular, glycosyl compound biosynthetic processes are important for schistosome development, and schistosome glycoconjugates play an important role in the evasion mechanisms that worms utilize to evade host immunological responses [57, 58]. Regarding resistance to re-infection and self-curing in water buffaloes, it is generally accepted that these phenomenon are mainly due to specific immune responses produced by the animals in response to schistosome infection [59]. Studies have reported that some individuals develop partial resistance to re-infection after schistosomiasis infection and treatment and that high levels of isotype antibody IgE and low levels of IgG4 are closely related to soluble egg antigens (SEA) and adult worm antigen (SWA) in the resistant population [33,60,61]. We also found that a subset of transcripts involved in glycosylation, including beta-1, 3-galactosyl-O-glycosyl-glycoprotein beta-1, 6-N-acetylglucosaminyltransferase 3 (Sjp_0048330) and putative glycosyltransferase (Novel03665), were downregulated in worms recovered from re-infected water buffaloes. Glycosylation is a complicated biological process [62] and the global level of glycosylation and the functions of glycoconjugates in worms recovered from re-infected water buffaloes or other hosts that are resistant to re-infection require further study

Annexins belong to a multigene family of calciumdependent phospholipid-binding proteins, many members of which have been identified in important eukaryotic phyla [63]. In humans, annexins interact closely with various cell membrane components to form networks on the cell surface that participate in the regulation of membrane organization, cell differentiation, migration and intracellular signaling by enzyme modulation and ion fluxes [64, 65]. Although annexins lack related signal peptides for secretion, many extracellular family members have been found to act as receptors for serum proteases on the endothelium and as inhibitors of neutrophil migration and blood coagulation [63]. In addition, some human annexin isoforms are involved in immunoregulatory functions such as the resolution of inflammation [66]. We identified four annexin domaincontaining protein-encoding genes (Sjp_0113480, Sjp_0122740, Sjp_0077960 and Sjp_0077970) that were downregulated in worms recovered from re-infected hosts. This result indicates that the differential expression of these genes might affect the survival and development of schistosomes in their definitive host. 
Information on the DEGs identified in the present study is essential to understanding the development of schistosomes in re-infected and primary-infected water buffaloes. In future studies, we will further investigate the $S$. japonicum genes identified in this study using in vitro culture or in vivo infection experiments using RNA interference (RNAi). We expect this to further contribute to our understanding of host-parasite relationships in re-infected and primary-infected water buffaloes and to provide helpful information for screening bovine schistosome vaccine candidates.

\section{Conclusions}

In summary, we employed an Illumina RNA-Seq platform to identify DEGs in adult $S$. japonicum worms recovered from re-infected and primary-infected water buffaloes. We found that the downregulation of some important genes may have contributed to reductions in worm counts and the maldevelopment of surviving worms in re-infected water buffaloes. Furthermore, worms may have developed compensatory mechanisms to survive in the disadvantageous host environment. The identification of these DEGs provides new insights into mechanisms of resistance of water buffaloes to re-infection as well as useful information for comprehending the interactions between S. japonicum and its host.

\section{Additional files}

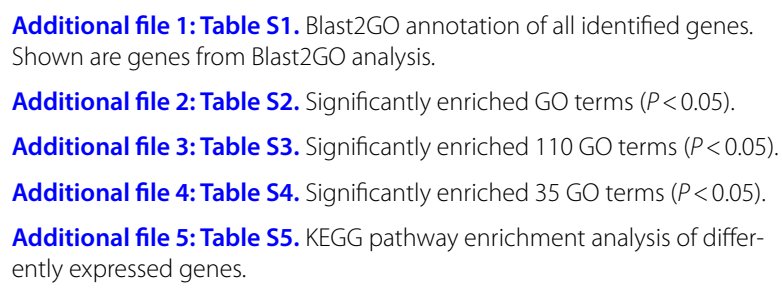

\section{Abbreviations}

RNA-Seq: RNA-sequencing; qPCR: quantitative PCR; GO: Gene Ontology; PZQ: praziquantel; DEGs: differentially expressed genes; IL: interleukin; IFN: interferon; IgG: immunoglobulin G; RIN: RNA integrity number; SRA: Sequence

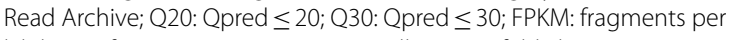
kilobase of transcript sequence per millions; FC: fold change; KEGG: Kyoto Encyclopedia of Genes and Genomes; ROS: reactive oxygen species; CcO: cytochrome c oxidase; ELOVL: elongation of the very long chain fatty acids; SEA: soluble egg antigens; SWA: soluble adult worm antigen; RNAi: RNA interference; AAALAC: Association for Assessment and Accreditation of Laboratory Animal Care International.

\section{Acknowledgements}

We would like to thank the members of our laboratory for their kind assistance with animal infections, worm perfusion and collection. We thank International Science Editing (http://www.internationalscienceediting.com) for editing this manuscript.

\section{Authors' contributions}

YDM and JML conceived and designed the experiments. YDM, CCH, HL, KL, ZQF, JJL and YMJ performed the experiments and analyzed the data. All authors read and approved the final manuscript.

\section{Funding}

This work was supported by the National Natural Science Foundation of China (Grant Number 31572218) and the Scientific and Technological Innovation Programme of the Chinese Academy of Agricultural Sciences.

\section{Availability of data and materials}

These sequencing data are available at the NCBI Sequence Read Archive (SRA) database at http://www.ncbi.nlm.nih.gov/sra under the Accession Number SRP168979.

\section{Ethics approval and consent to participate}

All procedures performed on animals in this study were conducted according to the guidelines of the Association for Assessment and Accreditation of Laboratory Animal Care International (AAALAC). The study protocol was approved by the Institutional Animal Care and Use Committee of the Shanghai Veterinary Research Institute, Chinese Academy of Agricultural Sciences, People's Republic of China.

\section{Consent for publication}

Not applicable.

\section{Competing interests}

The authors declare that they have no competing interests.

Received: 21 December 2018 Accepted: 6 July 2019

Published online: 11 July 2019

\section{References}

1. Fenwick A, Rollinson D, Southgate V. Implementation of human schistosomiasis control: challenges and prospects. Adv Parasitol. 2006;61:567-622

2. Chen MG. Assessment of morbidity due to Schistosoma japonicum infection in China. Infect Dis Poverty. 2014;3:16.

3. Cao ZG, Zhao YE, Lee WA, Wang TP. Towards the elimination of schistosomiasis japonica through control of the disease in domestic animals in The People's Republic of China: a tale of over 60 years. Adv Parasitol. 2016;92:269-306.

4. Zhang SQ, Sun CS, Wang M, Lin DD, Zhou XN, Wang TP. Epidemiological features and effectiveness of schistosomiasis control programme in Lake and Marshland Region in The People's Republic of China. Adv Parasitol. 2016;92:39-71.

5. Couto FF, Coelho PM, Araújo N, Kusel JR, Katz N, Jannottipassos LK, et al. Schistosoma mansoni: a method for inducing resistance to praziquantel using infected Biomphalaria glabrata snails. Mem Inst Oswaldo Cruz. 2011;106:153-7.

6. Li HJ, Liang YS, Dai JR, Wang W, Qu GL, Li YZ, et al. Studies on resistance of Schistosoma to praziquantel XIV experimental comparison of susceptibility to praziquantel between PZQ-resistant isolates and PZQ-susceptible isolates of Schistosoma japonicum in stages of adult worms, miracidia and cercariae. Chin J Schistosomiasis Control. 2011;23:611-9.

7. Shi L, Li W, Wu F, Zhang JF, Yang K, Zhou XN. Epidemiological features and control progress of schistosomiasis in Waterway-Network Region in P. R. China. Adv Parasitol. 2016;92:97.

8. Williams GM, Sleigh AC, Li Y, Feng Z, Davis GM, Chen H, et al. Mathematical modelling of schistosomiasis japonica: comparison of control strategies in the People's Republic of China. Acta Trop. 2002;82:253-62.

9. Mcmanus DP, Gray DJ, Ross AG, Williams GM, He HB, Li YS. Schistosomiasis research in the dongting Lake Region and its impact onlocal and national treatment and control in China. PLoS Negl Trop Dis. 2011;5:e1053.

10. Shi YE, Jiang CF, Han JJ, Li YL, Ruppel A. Schistosoma japonicum: an ultraviolet-attenuated cercarial vaccine applicable in the field for water buffaloes. Exp Parasitol. 1990;71:100-6.

11. Wu HW, Fu ZQ, Lu K, Pond-Tor S, Meng R, Hong Y, et al. Vaccination with recombinant paramyosin in Montanide ISA206 protects 
against Schistosoma japonicum infection in water buffalo. Vaccine. 2017;35:3409-15.

12. Sequencing SJG, Consortium FA. The Schistosoma japonicum genome reveals features of host-parasite interplay. Nature. 2010;460:345-51.

13. Berriman M, Haas BJ, Loverde PT, Wilson RA, Dillon GP, Cerqueira GC, et al. The genome of the blood fluke Schistosoma mansoni. Nature. 2016;460:352-8.

14. Cai P, Liu S, Xianyu P, Hou N, Gobert GN, Mcmanus DP, et al. Comprehensive transcriptome analysis of sex-biased expressed genes reveals discrete biological and physiological features of male and female Schistosoma japonicum. PLoS Negl Trop Dis. 2016;10:e0004684.

15. Jones MK, Higgins T, Stenzel DJ, Gobert GN. Towards tissue specific transcriptomics and expression pattern analysis in schistosomes using laser microdissection microscopy. Exp Parasitol. 2007;117:259-66.

16. Han H, Peng J, Yang H, Min Z, Han Y, Fu Z, et al. Comparison of the differential expression miRNAs in Wistar rats before and 10 days after $S$. japonicum infection. Parasit Vectors. 2013;6:120.

17. Hong Y, Peng J, Jiang W, Fu Z, Liu J, Shi Y, et al. Proteomic analysis of schistosoma japonicum schistosomulum proteins that are differentially expressed among hosts differing in their susceptibility to the infection. Mol Cell Proteomics. 2011;10(M110):006098.

18. Peng J, Han H, Gobert GN, Yang H, Jiang W, Wang X, et al. Differential gene expression in Schistosoma japonicum schistosomula from Wistar rats and BALB/C mice. Parasit Vectors. 2011;4:155.

19. Yang J, Feng X, Fu Z, Yuan C, Hong Y, Shi Y, et al. Ultrastructural observation and gene expression profiling of Schistosoma japonicum derived from two natural reservoir hosts, water buffalo and yellow cattle. PLoS ONE. 2012;7:e47660.

20. He YX, Salafsky B, Ramaswamy K. Host-parasite relationships of Schistosoma japonicum in mammalian hosts. Trends Parasitol. 2001;17:320-4.

21. Li YS, Mcmanus DP, Lin DD, Williams GM, Harn DA, Ross AG, et al. The Schistosoma japonicum self-cure phenomenon in water buffaloes: potential impact on the control and elimination of schistosomiasis in China. Int J Parasitol. 2014;44:167-71.

22. Wang T, Zhang S, Wu W, Zhang G, Lu D, Ornbjerg N, Johansen M. Treatment and reinfection of water buffaloes and cattle infected with Schistosoma japonicum in Yangtze River Valley, Anhui province, China. J Parasitol. 2006;92:1088-91.

23. He C, Mao Y, Zhang X, Li H, Lu K, Fu Z, et al. High resistance of water buffalo against reinfection with Schistosoma japonicum. Vet Parasitol. 2018;261:18-21.

24. Mcwilliam HEG, Piedrafita D, Li Y, Zheng M, He Y, Yu X, et al. Local immune responses of the Chinese water buffalo, bubalus bubalis, against Schistosoma japonicum larvae: crucial insights for vaccine design. PLoS Negl Trop Dis. 2013;7:e2460.

25. Biolchini Cde L, Neves RH, Hulstijn M, Gomes DC, Machado-Silva JR. Development of Schistosoma mansoni worms in mice analyzed by bright field and confocal microscopy. Mem Inst Oswaldo Cruz. 2006;101:261-5.

26. Neves RH, De LBC, Machadosilva JR, Carvalho JJ, Branquinho TB, Lenzi HL, et al. A new description of the reproductive system of Schistosoma mansoni (Trematoda: Schistosomatidae) analyzed by confocal laser scanning microscopy. Parasitol Res. 2005;95:43-9.

27. Wang $X, X u X$, Lu X, Zhang Y, Pan W. Transcriptome bioinformatical analysis of vertebrate stages of Schistosoma japonicum reveals alternative splicing events. PLOS ONE. 2015;10:e0138470.

28. Zhang FK, Zhang XX, Elsheikha HM, He JJ, Sheng ZA, Zheng WB, et al. Transcriptomic responses of water buffalo liver to infection with the digenetic fluke Fasciola gigantica. Parasit Vectors. 2017;10:56.

29. Kim D, Langmead B, Salzberg SL. HISAT: a fast spliced aligner with low memory requirements. Nat Methods. 2015;12:357-60.

30. Pertea M, Pertea GM, Antonescu CM, Chang TC, Mendell JT, Salzberg SL. StringTie enables improved reconstruction of a transcriptome from RNAseq reads. Nat Biotechnol. 2015;33:290-5.

31. Götz S, García-Gómez JM, Terol J, Williams TD, Nagaraj SH, Nueda MJ, et al. High-throughput functional annotation and data mining with the Blast2GO suite. Nucleic Acids Res. 2008;36:3420-35.

32. Livak KJ, Schmittgen TD. Analysis of relative gene expression data using real-time quantitative $P C R$ and the 2(-delta delta $C(T)$ ) method. Methods. $2001 ; 25: 402-8$
33. Zhang Z, Wu H, Chen S, Hu L, Xie Z, Qiu Y, et al. Association between IgE antibody against soluble egg antigen and resistance to reinfection with Schistosoma japonicum. Trans R Soc Trop Med Hyg. 1997;91:606-8.

34. Ho YH. On the host specificity of Schistosoma japonicum. Chin Med J. 1963;82:403-14.

35. Yang J, Fu Z, Feng X, Shi Y, Yuan C, Liu J, et al. Comparison of worm development and host immune responses in natural hosts of Schistosoma japonicum, yellow cattle and water buffalo. BMC Vet Res. 2012;8:25.

36. Zhai Q, Fu Z, Hong Y, Yu X, Han Q, Lu K, et al. iTRAQ-based comparative proteomic analysis of adult Schistosoma japonicum from water buffalo and yellow cattle. Front Microbiol. 2018;9:99.

37. Yang J, Fu Z, Hong Y, Wu H, Jin Y, Zhu C, et al. the differential expression of immune genes between water buffalo and yellow cattle determines species-specific susceptibility to Schistosoma japonicum infection. PLoS ONE. 2015;10:e0130344.

38. Liu F, Lu J, Hu W, Wang SY, Cui SJ, Chi M, et al. New perspectives on hostparasite interplay by comparative transcriptomic and proteomic analyses of Schistosoma japonicum. PLoS Pathog. 2006;2:e29.

39. Hu W, Brindley PJ, Mcmanus DP, Feng Z, Han ZG. Schistosome transcriptomes: new insights into the parasite and schistosomiasis. Trends Mol Med. 2004;10:217-25

40. Blesa J, Trigo-Damas I, Dileone M, Del Rey NL, Hernandez LF, Obeso JA. Compensatory mechanisms in Parkinson's disease: Circuits adaptations and role in disease modification. Exp Neurol. 2017;298 Pt B:148-61.

41. Barrey C, Roussouly P, Le Huec JC, D’Acunzi G, Perrin G. Compensatory mechanisms contributing to keep the sagittal balance of the spine. Eur Spine J. 2013;22(Suppl. 6):S834-41.

42. Wang MK, Gaither T, Phelps A, Cohen R, Baskin L. The incidence and durability of compensatory hypertrophy in pediatric patients with solitary kidneys. Urology. 2019. https://doi.org/10.1016/j.urology.2019.04.003.

43. Chakroborty S, Kim J, Schneider C, West AR, Stutzmann GE. Nitric oxide signaling is recruited as a compensatory mechanism for sustaining synaptic plasticity in Alzheimer's disease mice. J Neurosci. 2015;35:6893-902.

44. Laha T, Brindley PJ, Verity CK, Mcmanus DP, Loukas A. pido, a non-long terminal repeat retrotransposon of the chicken repeat 1 family from the genome of the Oriental blood fluke, Schistosoma japonicum. Gene. 2002;284:149-59.

45. Gudi R, Zou C, Dhar J, Gao Q, Vasu C. Centrobin-centrosomal protein 4.1-associated protein (CPAP) interaction promotes CPAP localization to the centrioles during centriole duplication. J Biol Chem. 2014;289:15166-78.

46. Loganklumpler FJ, Silva ND, Boehme U, Rogers MB, Velarde G, Mcquillan JA, et al. GeneDB — an annotation database for pathogens. Nucleic Acids Res. 2012;40(Database issue):98-108.

47. Michel B, Ehrlich SD, Uzest M. DNA double-strand breaks caused by replication arrest. EMBO J. 1997;16:430-8.

48. Game JC. DNA double-strand breaks and the RAD50-RAD57 genes in Saccharomyces. Semin Cancer Biol. 1993;4:73-83.

49. Oliveira MP, Soares JBRC, Oliveira MF. Sexual preferences in nutrient utilization regulate oxygen consumption and reactive oxygen species generation in Schistosoma mansoni: potential implications for parasite redox biology. PLoS ONE. 2016;11:e0158429.

50. Esparza I, Ruppel A, Mestan J, Krammer PH. Preactivation of macrophages in mice acutely infected with Schistosoma mansoni. Immunobiology. 1988;177:105-19.

51. Smith JM, Mkoji GM, Prichard RK. Depression of hydrogen peroxide dependent killing of schistosomula in vitro by peritoneal exudate cells from Schistosoma mansoni infected mice. Am J Trop Med Hyg. 1989;40:186.

52. Capaldi RA. Structure and function of cytochrome c oxidase. Annu Rev Biochem. 1990;59:569-96.

53. Srinivasan S, Avadhani NG. Cytochrome c oxidase dysfunction in oxidative stress. Free Radic Biol Med. 2012;53:1252-63.

54. Sayed AA, Williams DL. Biochemical characterization of 2-Cys peroxiredoxins from Schistosoma mansoni. J Biol Chem. 2004;279:26159.

55. Kuntz AN, Davioudcharvet E, Sayed AA, Califf LL, Dessolin J, Arnér ES, et al. Thioredoxin glutathione reductase from Schistosoma mansoni: an essential parasite enzyme and a key drug target. PloS Med. 2007;4:e206

56. Yang J, Fu Z, Feng X, Shi Y, Yuan C, Liu J, et al. Comparison of worm development and host immune responses in natural hosts of schistosoma japonicum, yellow cattle and water buffalo. BMC Vet Res. 2012;8:25. 
57. Hokke CH, Deelder AM. Schistosome glycoconjugates in host-parasite interplay. Glycoconj J. 2001;18:573-87.

58. Khoo KH, Chatterjee D, Caulfield JP, Morris HR, Dell A. Structural mapping of the glycans from the egg glycoproteins of Schistosoma mansoni and Schistosoma japonicum: identification of novel core structures and terminal sequences. Glycobiology. 1997;7:663-77.

59. Wang WQ, Liu S, Song GC, Xu YX, Cao JP, Chen JX. Schistosoma japonicum: screening of cDNA library with sera from self-cured water buffaloes (Bos buffelus). Chin J Parasitol Parasit Dis. 2003:21:286-8.

60. Oliveira RR, Figueiredo JP, Cardoso LS, Jabar RL, Souza RP, Wells MT, et al. Factors associated with resistance to Schistosoma mansoni infection in an endemic area of Bahia, Brazil. Am J Trop Med Hyg. 2012;86:296-305.

61. Li Y, Sleigh AC, Ross AGP, Li Y, Zhang X, Williams GM, et al. Human susceptibility to Schistosoma japonicum in China correlates with antibody isotypes to native antigens. Trans R Soc Trop Med Hyg. 2001;95:441-8.
62. Mickum ML, Prasanphanich NS, Heimburg-Molinaro J, Leon KE, Cummings RD. Deciphering the glycogenome of schistosomes. Front Genet. 2013;5:262.

63. Gerke V, Moss SE. Annexins: from structure to function. Physiol Rev. 2002:82:331-71.

64. Moss SE, Morgan RO. The annexins. Genome Biol. 2004;5:1-8.

65. Gerke V, Creutz CE, Moss SE. Annexins: linking Ca2+ signalling to membrane dynamics. Nat Rev Mol Cell Biol. 2005;6:449-61.

66. Perretti M, Dacquisto F. Annexin A1 and glucocorticoids as effectors of the resolution of inflammation. Nat Rev Immunol. 2009;9:62-70.

\section{Publisher's Note}

Springer Nature remains neutral with regard to jurisdictional claims in published maps and institutional affiliations.
Ready to submit your research? Choose BMC and benefit from:

- fast, convenient online submission

- thorough peer review by experienced researchers in your field

- rapid publication on acceptance

- support for research data, including large and complex data types

- gold Open Access which fosters wider collaboration and increased citations

- maximum visibility for your research: over $100 \mathrm{M}$ website views per year

At BMC, research is always in progress.

Learn more biomedcentral.com/submissions 